\title{
Activities to Teaching Electric Field Based on Physics by Inquiry
}

\author{
Manuel Sandoval Martínez \\ Universidad Politécnica del Golfo de México, \\ Tabasco, México
}

\author{
César Eduardo Mora Ley \\ Instituto Politécnico Nacional, \\ México City, México
}

\begin{abstract}
We designed and used a series of activities (named activities to teaching electric field (ATEF)) based on the Physics by Inquiry (PBI) strategy to teaching the electric field concept with university students. We used a concentration factor tool to assess the effectiveness of those activities used during three weeks of instruction. Results indicate that students who had traditional teaching obtained a very tiny gain (less than 1\%); concentration factors indicate that most of their responses fall into a random area, which is not favorable. On the other hand, the experimental group using our activities had greater gains $(>10 \%)$ than the control group. Concentration factors showed that after instruction, students' mental models changed toward a favorable pattern about comprehension of electric field concept and Coulomb's law. A hypothesis test of two samples indicated that there is a significant difference between both traditional teaching and ATEF based on PBI.
\end{abstract}

Keywords: activities to teaching electric field (ATEF), concentration factor, Physics by Inquiry (PBI)

\section{Introduction}

Research on teaching in Electricity and Magnetism (E \& M) has been very important in recent years. Several researchers found that students have incorrect beliefs in E \& M topics, which are related with similar beliefs in Newtonian mechanics. Catalán, Caballero, and Moreira (2010) found that students tend to confuse vector strength with vector operator, both in Newtonian mechanics and E \& $\mathrm{M}$ courses. Other results indicate that students can identify scalar and vector topics (Llancaqueo, Caballero, \& Moreira, 2003); however, they have difficulties representing them mathematically. Furió and Guisasola (1999) found that for most students, electric field is useful for computing electric force; but they do not realize that electric field causes the interaction of charged objects. Another difficulty found by researchers (Alvarez, 2010; Chabay, Sherwood, \& Beichner, 2006) was the comprehension of entities or mathematics object that appears in the formalization of electromagnetism laws, such as line integrals, surface integrals, the flux concept, etc.; so, students simultaneously face both difficulties associated with learning physics and new mathematics tools. Allain (2001) indicated that electric field concept is the most difficult to learn (more than any concept in Newtonian mechanics) because students do not perceive it as a real object. Another very important factor is the location of physics courses on the curricular map for some university careers. This was a problem that we found in previous work (Sandoval \& Mora, 2010a) at the technological system in Mexico. For example, for a 
mechatronic career, E \& M is placed in the third semester, but the Newtonian mechanics course is taken in the fourth semester. This makes it difficult for some students to pass E \& M, because they have too little background in physics and mathematics in order to enroll in this subject. A very important concept to understand electric field is electric field line or force line, which was proposed by Faraday. The advantages of force lines give a vector field as geometrical and visual interpretation (Berkson, 1985; Bradley, 1991; Pocovi \& Finley, 2002). However, despite this big advantage, university students are unable to understand force lines. Galili (1995) found that $70 \%-80 \%$ of students identify the force line at the location where a charge is placed as the actual trajectory that a free charge would follow in that electric field region. In previous work (Sandoval \& Mora, 2009), we found that most of university students have difficulties relating electric field and electric potential. Also, some students consider that electric force that a uniform electric field exerts on a charged object is zero. We also found that a high percentage of students think that an electric force exerted on a charge while crossing an equipotential line could change its direction. Other results (Sandoval \& Mora, 2010b) indicate that most university students think that the strength of the electric force caused by uniform electric field (inside two parallel plates) depends on the point where the charge is placed. A most common description by students is, "If a positive charge is near to positive plate, the strength of the force is the biggest and near to negative plate, the force will be the smallest; if charge is negative, the opposite occurs".

Another point to consider is the sensibility to apply the assessment instruments. Some researchers found that students' performance decreased after instruction, but it depended on the instruction used. Sayre and Heckler (2009) showed that correct responses related to electric field between two opposite charge increase when they study that topic in the classroom and the knowledge remains for a certain time, however, when they start to study electric potential, there is a decrease in students' performance about electric field. If teachers expose the correct scientific ideas, students do not necessarily abandon their previous ideas, which they can keep with no change after long periods of instruction (Bohigas \& Periago, 2010).

\section{Concentration Factor}

Our data were analyzed using a powerful tool named concentration factor, proposed by Bao and Redish (2001). It makes a deep analysis concerning classroom and individual student test data leading to a plot with three regions: no model, two models, and one model. For a multiple-choice test, the concentration factor is computed as:

$$
C=\frac{\sqrt{5}}{\sqrt{5}-1}\left(\frac{\sqrt{n_{a}^{2}+n_{b}^{2}+n_{c}^{2}+n_{d}^{2}+n_{e}^{2}}}{N}-\frac{1}{\sqrt{5}}\right)
$$

where $n_{i}^{2}$ is the number of possible choices by students for some items, and $N$ is the total number of students. The response patterns are a kind of students' performance measure and indicate if they have dominant previous ideas. In fact, the response pattern variation indicates how students' performance is after instruction changes. For example, some responses with low score and high concentration (LH) indicate a strong misconception (incorrect model); the pattern of low score and low concentration (LL) indicates that most of students do not have a dominant model and their responses could be random choice. Following Bao and Redish's (2001) ideas, we can use the following interpretation:

1. No model: Responses are concentrated on more than three options;

2. One model: Most of the responses are concentrated on one option; 
3. Two models: Most of the responses are concentrated on two options (one correct and one incorrect).

If we compare pre- and post- test results, the response pattern variation can be useful. For example, if there is a change from LL to LH, instruction has problems because students move in the incorrect way. If there is a change from LH to high score and high concentration $(\mathrm{HH})$, the instruction is successful; a change from LL to median score and median concentration (MM) means that the instruction is not a success, yet, but is moving in the correct way. Zavala and Alarcón (2008) used this tool with university students in the Technology Institute in Monterrey, Mexico, in order to analyze students' performance using the Conceptual Survey in Electricity (CSE) (Maloney, O'Kuma, Hieggelke, \& Van Heuvelen, 2001). They found that in some areas, students could reach a good level, but in other areas, the level was very low. We obtain similar results with that work, see section "Analysis With Concentration Factor". In agreement with Bao's theory, response patterns provide a measure of students' performance and indicate if students improve their reasoning and mental models.

\section{Methodology}

Students whom participated in the experiment were enrolled in the third semester at the Technology Institute of Comalcalco, in Tabasco, Mexico. They were enrolled in the E \& M course for the first time. We told both the control group and the experimental group that pre-test was very important for the instructor in order to know about their current conceptual level, and we did not give them extra points for exams in class. All students took the CSE via Web. The goal of this work is to study the comprehension level of the electric field concept by university students. The experimental group was chosen by a random process. Data were collected via Web, both pre- and post- tests. Activities used in the study were designed following McDermont's methodology, Physics by Inquiry (PBI) (McDermont \& Shaffer, 2001). Our activities, named activities to teaching electric field (ATEF), are related to socio-constructivism. For this reason, students did their analysis making teams with three or four students (Epinosa, 2003; D. Jhonson \& R. Jhonson, 1989). Each activity was designed in order to help students understand the effects that electric fields produce on a particle charge using geometric-qualitative arguments, attending the physics concept involved.

\section{Analysis of Data}

\section{Coulomb's Law}

In this section, we exhibit students' mental models before and after instruction in both the control group and the experimental group. Table 1 shows the scores and mental models chosen by them for each item. We can see in the control group that there is a small improvement in their mental models (Item 17). However, for items 8 and 16, students maintained the correct model before and after instruction (traditional), but the score is not high. The other items supported the null and incorrect models. On the other hand, the experimental group had good changes in most of their previous mental models. It is observed that the score by mental model 1 is the highest; for example, items 8,16 , and 17 reach a score above $50 \%$. This is a big difference between both groups.

\section{Electric Field}

Questions about electric field were the most difficult for both groups. For example, the null and incorrect models appeared in the control group (see Table 2), we could also see a decrease in students' performance in 
Item 9, where they had a correct model in the pre-test, but after instruction, their mental model changed to the null model. In this way, traditional teaching tends to cause doubts in students on this topic. The experimental group reached the correct model for Item 9; at the beginning, students had incorrect model, but after instruction, they reached the correct model. We can deduce that electric field concept is very difficult to understand for students, principally on questions related to electric force exerted by an electric field and the relationship with Newton's second law.

Table 1

Coulomb's Law Mental Models

\begin{tabular}{|c|c|c|c|c|c|c|c|c|}
\hline & \multicolumn{4}{|c|}{ The control group } & \multicolumn{4}{|c|}{ The experimental group } \\
\hline & Pre $(\%)$ & Model pre & Post (\%) & Model post & Pre $(\%)$ & Model pre & Post $(\%)$ & Model post \\
\hline 1 & 33 & 3 & 40 & 3 & 48 & 3 & 37 & 3 \\
\hline 2 & 42 & 3 & 42 & 3 & 48 & 3 & 37 & 3 \\
\hline 3 & 36 & 2 & 39 & 2 & 30 & 2 & 43 & 1 \\
\hline 4 & 37 & 2 & 30 & 2 & 28 & 1 & 33 & 2 \\
\hline 5 & 34 & 3 & 33 & 3 & 33 & 2 & 33 & 3 \\
\hline 6 & 39 & 2 & 33 & 2 & 50 & 2 & 50 & 1 \\
\hline 7 & 27 & 2 & 30 & 2 & 30 & 2 & 34 & 3 \\
\hline 8 & 34 & 1 & 35 & 1 & 27 & 2 & 57 & 1 \\
\hline 16 & 45 & 1 & 44 & 1 & 55 & 1 & 80 & 1 \\
\hline 17 & 39 & 2 & 45 & 1 & 50 & 2 & 48 & 1 \\
\hline
\end{tabular}

Table 2

Change Model on Electric Force and Electric Field

\begin{tabular}{|c|c|c|c|c|c|c|c|c|c|c|c|c|c|c|c|c|c|}
\hline \multirow{3}{*}{ Item } & \multicolumn{8}{|c|}{ Electric field } & \multicolumn{9}{|c|}{ Force and electric field } \\
\hline & \multicolumn{4}{|c|}{ The control group } & \multicolumn{4}{|c|}{ The experimental group } & \multirow{2}{*}{ Item } & \multicolumn{4}{|c|}{ The control group } & \multicolumn{4}{|c|}{ The experimental group } \\
\hline & $\begin{array}{l}\text { Pre } \\
(\%)\end{array}$ & $\begin{array}{l}\text { Model } \\
\text { pre }\end{array}$ & $\begin{array}{l}\text { Post } \\
(\%)\end{array}$ & $\begin{array}{l}\text { Model } \\
\text { post }\end{array}$ & $\begin{array}{l}\text { Pre } \\
(\%)\end{array}$ & $\begin{array}{l}\text { Model } \\
\text { pre }\end{array}$ & $\begin{array}{l}\text { Post } \\
(\%)\end{array}$ & $\begin{array}{l}\text { Model } \\
\text { post }\end{array}$ & & $\begin{array}{l}\text { Pre } \\
(\%)\end{array}$ & $\begin{array}{l}\text { Model } \\
\text { pre }\end{array}$ & $\begin{array}{l}\text { Post } \\
(\%)\end{array}$ & $\begin{array}{l}\text { Model } \\
\text { post }\end{array}$ & $\begin{array}{l}\text { Pre } \\
(\%)\end{array}$ & $\begin{array}{l}\text { Model } \\
\text { pre }\end{array}$ & $\begin{array}{l}\text { Post } \\
(\%)\end{array}$ & $\begin{array}{l}\text { Model } \\
\text { post }\end{array}$ \\
\hline 9 & 34 & 1 & 24 & 3 & 33 & 2 & 37 & 1 & 11 & 35 & 1 & 36 & 1 & 50 & 1 & 67 & 1 \\
\hline 10 & 26 & 2 & 27 & 2 & 45 & 2 & 50 & 2 & 12 & 26 & 2 & 26 & 3 & 33 & 2 & 37 & 1 \\
\hline 13 & 31 & 3 & 39 & 3 & 45 & 3 & 60 & 3 & 14 & 24 & 2 & 33 & 1 & 33 & 1 & 60 & 1 \\
\hline 15 & 29 & 3 & 34 & 2 & 40 & 3 & 33 & 3 & 18 & 27 & 2 & 25 & 1 & 28 & 2 & 43 & 1 \\
\hline 20 & 30 & 2 & 37 & 2 & 35 & 2 & 53 & 2 & 19 & 29 & 2 & 25 & 2 & 28 & 3 & 50 & 3 \\
\hline
\end{tabular}

\section{Electric Force and Electric Field}

The last classification is related to electric force and electric field. Table 2 shows the results about different students' mental models before and after instruction. We can see in the control group that students obtained the correct model for just three questions $(60 \%)$, but the score was low. A better situation occurred in Item 11, where they considered that the electric force excerted on a particle charged, in an uniform electric field, should be the same at every point; however, they had a problem finding the direction of the force on a negative charge because they think electric force is in the same direction, like a force on a positive charge. The experimental group had a favorable change in their mental models and tended toward the correct model (80\%). Their scores were also higher than the control group. We found that most students know how to identify the acceleration caused by the electric force that a uniform electric field exerts on a charge. In general, the experimental group shows a better comprehension on those topics than the control group. 


\section{Analysis With Concentration Factor}

The control group was taught using traditional instruction, i.e., the telling model, and then, resolving some problems by a classic textbook for engineering students (Serway, Jewtt, Soutas-Little, Inman, \& Balint, 2010). The control group had 253 students. Using the concentration factor on data, we found that most of the responses had a very low score and concentration factor; 19 patterns of LL and one pattern of median score and low concentration (ML). Figure 1(a) shows a plot for pre- and post- tests; black diamonds represent pre-test results and circles represent post-test results. Small asterisk and big asterisk represent pre- and post- tests average respectively. We can see that $100 \%$ of responses (pre-test) fall in random zone (no model region), $95 \%$ are style LL, and 5\% are style ML. Both LL and ML patterns indicate that most of students chose their answers randomly. Post-test was applied two weeks after finishing those topics via Web. Figure 1(a) shows that students' performance on those topics remained very low because response patterns (circles) that they had at the beginning of the course had practically no change; all responses fall again in the random zone. It seems that traditional teaching is not enough to teach electrostatics topics; these complex concepts remain incomprehensible for these students. It is observed that the differences on post-test and pre-test averages are very small. We can obtain normalizing gain (Hake, 1998) as follows:

$$
\langle g\rangle=\frac{\%\left\langle S_{f}\right\rangle-\%\left\langle S_{i}\right\rangle}{100-\%\left\langle S_{i}\right\rangle}
$$

where $\%\left\langle S_{i}\right\rangle$ and $\%\left\langle S_{f}\right\rangle$ represent respectively the average of correct pre- and post- test scores. Normalized gain was $0.7 \%$ (for the control group), which is a very tinny value and indicates that traditional instruction induces no conceptual change in students. In Figure 1(a), we can observe that the distance between small and big asterisk is very small, and according to Bao, instruction is in the wrong direction.

The experimental group had 45 students at the beginning of the semester. With this group, we applied the methodological procedures described in this paper. Analyzing the data in pre-test, we found 15 patterns of LL, three patterns of LM, and two patterns of MM. At first sight, it seems that the experimental group had more interest in the pre-test than control group because five questions did not fall in the random zone, although the number of questions in this zone is very high.

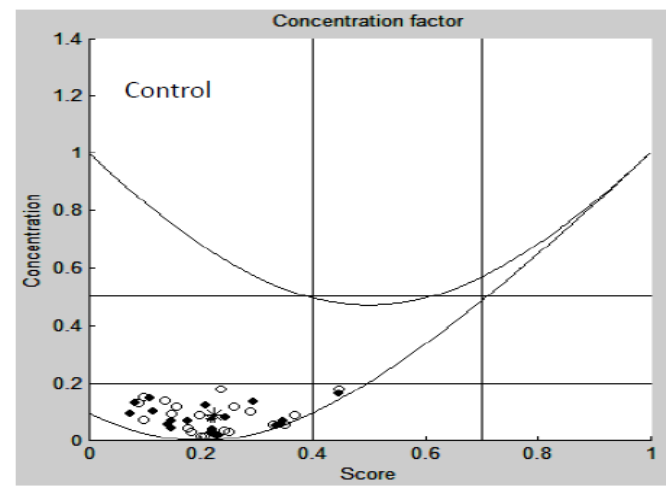

(a) Response patterns by the control group.

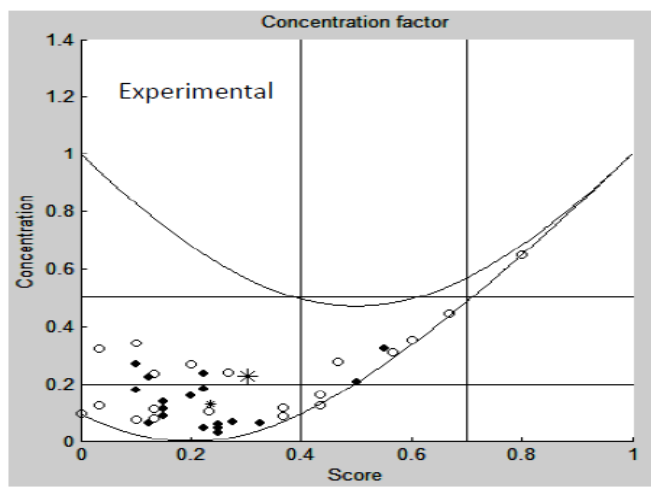

(b) Response patterns by the experimental group.

Figure 1. Patterns of response by both groups.

Figure 1(b) shows a plot of response patterns by the experimental group. In the pre-test, we observe that $75 \%$ of students fall in the random zone (LL), $15 \%$ in region LM (two incorrect models), and $10 \%$ in region 
MM (one correct and one incorrect model). Post-test was applied one week following the instruction for Coulomb's law and electric field concept. Response patterns in the experimental group show considerable improvement. The percentage in LL zone decreased to $50 \%$ (25\% less than the pre-test). The LM zone reached $25 \%(10 \%$ more than the pre-test); although this zone is not good, we should remark that students did not choose their answers randomly; even though their mental models are wrong, we can obtain information about their reasoning (we can not do that for the LL zone). On the other hand, MM (one correct and one incorrect) zone increased to $20 \%$ (50\% more than pre-test), which means that students' reasoning improved step by step using our activities (we have four questions in this zone). Figure 1(b) shows that one question reached HH zone, indicating that students could obtain an excellent comprehension of that topic. This result indicates that our methodology maybe is not successful yet, but is on the correct path. It is observed that the distance between the small and big asterisk is larger than the control group. Normalized gain in this group was $10.46 \%$, which is larger than the control group (0.7). This value was small, but was a considerable improvement in the comprehension mentioned. We did a hypothesis test with $95 \%$ of security and $Z=1.96$. With the data obtained and a hypothesis test of two samples, we found $\overline{x_{1}}=6.3, \overline{x_{2}}=4.45$, and $Z=2.1577$. These values indicate that there is a meaningful difference between both traditional teaching and PBI. During instruction, we observed a high interest among students to resolve ATEF. They were very interesting in improving their analysis; students were engaged to do the activities by themselves and chat with their classmates in order to share their reasoning. Moreover, analysis of responses to ATEF allowed us to have a more wide vision about evolution of students' reasoning; we could observe that most of their individual responses commonly were in the wrong way. However, when they shared their response in teams (socio-constructivism), the comprehension about topics improved very well in most cases.

\section{Conclusion}

Responses to ATEF gave us a clear evaluation of these activities in order to provoke better motivation among students to understand a complex concept, such as electric field. Analyzing the responses on each activity, we found that students' reasoning was increasing step by step because students' explanations had better physics arguments; ATEF were designed in this way, because complexity increases progressively and tends to provoke a high demand in their reasoning. The concentration factor allowed us to analyze in more detail the weaknesses and strengths about instruction proposed in this work; we found that traditional teaching is not enough to change conceptual models in students in order to adopt correct models. We deduce that because normalized gain was very tinny in the control group (less than 1\%) and response patterns in pre- and post- test fall in the random zone, indicating that students do not adopt a correct model in electrostatics topics. The data analyzed allow us to assert that the strategy proposed in this work is on the correct path, even if the normalized gain generated is low (near to $11 \%$ ). The concentration factor allowed us to observe that students could change their wrong models for better accepted models. Response pattern percentage increased to $20 \%$ in the MM zone and reached HH zone (mastered concept) with $80 \%$ of correct response. Furthermore, the response pattern in the random zone decreased to $50 \%$; LM zone increased to $25 \%$. This zone is not favorable, but we can obtain good information about the concept that students do not understood very well and the instructor can improve his/her class and change (if necessary) the goals in the instruction. This indicates that ATEF improve conceptual learning in electrostatics among students in the experimental group and traditional teaching is not enough to provoke a change in their mental models. 


\section{References}

Alvarez, T. (2010). La visualización de conceptos matemáticos y el aprendizaje del electromagnetismo (Math concepts view and electromagnetics learning). Latin American Journal of Physics, 4, 143-148.

Allain, R. (2001). Investigating the relationship between student difficulties with the concept of electric potential and the concept of rate of change (Ph.D. dissertation, Graduate Faculty, North Carolina State University).

Bao, L., \& Redish, E. (2001). Concentration analysis: A quantitative assessment of student state. American Journal of Physics, 69, 7.

Berkson, W. (1985). Las teorías de los campos de fuerza: Desde Faraday hasta Einstein (Force field theory: From Faraday to Einstein). Madrid, España: Alianza Editorial.

Bohigas, X., \& Periago, M. (2010). Modelos mentales alternativos de los alumnos de segundo curso de ingeniería sobre la ley de Coulomb y el campo eléctrico (Alternative mental models of university students about Coulomb's law). Revista Electrónica de Investigación Educativa, 12, 1-19.

Bradley, J. (1991). Repeating the electromagnetic experiments of Michael Faraday. Physics Education, 26, $284-288$.

Catalán, L., Caballero, C., \& Moreira, M. (2010). Niveles de conceptualización en el campo conceptual de la inducción electromagnética. Un estudio de caso (Conceptualization level on conceptual field of electromagnetic induction). Latin American Journal of Physics, 4, 126-142.

Chabay, R., Sherwood, B., \& Beichner, R. (2006). Evaluating and electricity and magnetism assessment tool: Brief electricity and magnetics assessment. Physical Review Special Topics-Physics Education Research, 2, 1-6.

Epinosa, G. (2003). Teamwork in the classroom. Ministerio de la Educación, 23, 1-11.

Furió, C., \& Guisasola, J. (1999). Concepciones alternativas y dificultades de aprendizaje en electrostática: Selección de cuestiones elaboradas para su detección y tratamiento (Misconception and learning dificulties on electrostatics: Question alaborate for detection and processing). Enseñanza de las Ciencias, 17, 441-452.

Galili, I (1995). Mechanics background influences students' conceptions in electromagnetism. International Journal of Science Education, 17, 371-387.

Hake, R. (1998). Interactive engagement vs. traditional methods: A six-thousand student survey of mechanics test data for introductory physics course. American Journal of Physics, 66, 64-74.

Jhonson, D., \& Jhonson, R. (1989). Learning together and alone: Cooperative, competitive and individualistic learning. New York, N.Y.: Holt, Reinhardt and Wiston.

Llancaqueo, A., Caballero, C., \& Moreira, M. (2003). El aprendizaje del concepto de campo de física: Una investigación exploratoria a la luz de la teoría de Vergnaud (Concept field learning in physics: A research based on Vergnaud's theory). Revista Brasileira de Ensino de Fisica, 25, 399-417.

Maloney, D., O'Kuma, T., Hieggelke, C., \& Van Heuvelen, A. (2001). Conceptual survey in electricity. American Journal of Physics, 69, 12-23.

McDermont, L., \& Shaffer, P. (2001). Tutoriales para Física introductoria (Physics by inquiry) (1st ed.). Buenos Aires: Pearson Education.

Pocovi, M., \& Finley, F. (2002). Line of force: Faraday's and students views. Science and Education, 11, 459-474.

Sandoval, M., \& Mora, C. (2009). Problemas de la enseñanza-aprendizaje en una clase tradicional: Dificultades en estudiantes de nivel superior para relacionar el campo eléctrico con el potencial eléctrico (Teaching-learning problems on traditional class: Student's dificulties on university students in order to link electric field with electric potencial). Paper presented at The VXII Taller Internacional: Nuevas Tendencias en la Enseñanza de la Física, Puebla, Pue.

Sandoval, M., \& Mora, C. (2010a). Análisis de la comprensión de las líneas de campo eléctrico en estudiantes de nivel superior (Analysis of student's comprehesion about electric field lines). Paper presented at The XVIII Taller Internacional: Nuevas Tendencias en la Enseñanza de la Física, Puebla, Pue.

Sandoval, M., \& Mora, C. (2010b). Study about reticular map on physics on engeeneringcarrer in technologic system. Latin American Journal of Physics, 4(1), 994-1001.

Sayre, E., \& Hecler, A. (2009). Peaks and decays of student knowledge in an introductory E \& M course. Physical Review Special Topics-Physics Education Research, 5, 1-5.

Serway, R., Jewtt, J., Soutas-Little, R., Inman, D., \& Balint, D. (2010). Física e ingeniería mecánica (Physics and mechanics engineering). Querétaro: Cengage Learning.

Zavala, G., \& Alarcón, H. (2008). Evaluation of instruction using the conceptual survey in electricity and magnetism in Mexico. In C. Henderson, M. Sabella, \& L. Hsu (Eds.), Proceeding of the Physics Education Research Conference (pp. 231-234). 